\title{
Pharmacists' training to improve inhaler technique of patients with COPD in Vietnam
}

This article was published in the following Dove Press journal:

International Journal of COPD

\author{
Tu-Son Nguyen ${ }^{1,2}$ \\ Thi Lien Huong Nguyen' \\ Thi Thuy Van Pham' \\ Susan $\mathrm{Hua}^{2}$ \\ Quy Chau Ngo3 \\ Shu Chuen $\mathrm{Li}^{2}$ \\ 'Department of Clinical Pharmacy, \\ Hanoi University of Pharmacy, Hanoi, \\ Vietnam; ${ }^{2}$ School of Biomedical \\ Sciences and Pharmacy, Faculty of \\ Health and Medicine, University of \\ Newcastle, Callaghan, NSW, Australia; \\ ${ }^{3}$ Respiratory Centre, Bach Mai \\ Hospital, Hanoi, Vietnam
}

Correspondence: Shu Chuen Li Room MSI08, Medical Sciences Building, University of Newcastle, University Drive, Callaghan, NSW 2308, Australia $\mathrm{Tel}+61249215921$

Fax +6I 249217903

Email shuchuen.li@newcastle.edu.au
Background: Incorrect use of inhalers is very common and subsequently leads to poor control of COPD. Among health care providers, pharmacists are in the best position to educate patients about the correct use of inhaler devices.

Objective: The objective of this study was to evaluate the impact of pharmacist-led training on the improvement of inhaler technique for COPD patients in Vietnam.

Patients and methods: For this pre- and post-intervention study, standardized checklists of correct use of metered-dose inhalers (MDIs) and dry powder inhalers (DPIs) were used to evaluate the inhaler technique. A scoring system (maximum score =8) was applied before and after training to guarantee assessment uniformity among pharmacists. Three methods including "face-to-face training", "teach-back" and "technique reminder label" were used. After the baseline evaluation (T0), the inhaler technique was reassessed after 1 month (T1), 3 months (T2), 6 months (T3) and 12 months (T4).

Results: A total of 211 COPD patients participated in the study. Before the training, a high rate of errors was recorded. After the training, the percentage of patients using MDIs and DPIs perfectly increased significantly $(p<0.05)$. The mean technique score for MDIs and DPIs improved from 6.0 (T0) to 7.5 (T3) and 6.9 (T4) and 6.7 (T0) to 7.6 (T3) and 7.2 (T4), respectively ( $p<0.05)$. The average training time was 6 minutes (T0) and 3 minutes (T3), respectively.

Conclusion: Pharmacist-led comprehensive inhaler technique intervention program using an unbiased and simple scoring system can significantly improve the inhaler techniques in COPD patients. Our results indicated a 3-month period as the optimal time period between training and retraining for maintaining the correct inhaler technique. The training would be highly feasible and suitable for implementing in the clinical setting. Our model of pharmacist-led training should be considered as an effective solution for managing COPD patients and better utilization of health care human resources, especially in a developing country like Vietnam.

Keywords: MDI, Turbuhaler ${ }^{\circledR}$, teaching and scoring methods, technique score, technique reminder label

\section{Introduction}

COPD, the fourth leading cause of death worldwide, is also a major cause of chronic morbidity all over the world, particularly in developing countries. As such, COPD places health care systems under high pressure because of its social and economic burdens, which are projected to increase in coming decades. ${ }^{1,2}$ In Vietnam, $10 \%$ of the population suffer from respiratory diseases, ${ }^{3}$ with $4.2 \%$ of people $>40$ years old affected by COPD due to the high smoking rate and continued exposure to other risk factors. COPD patients occupy $\sim 25 \%$ of beds in the respiratory wards of the hospitals. ${ }^{4}$ 
In the management of COPD, inhaler devices play a pivotal role in optimizing the delivery of medicines to the lungs. However, incorrect use of inhalers is very common and subsequently leads to poor control of respiratory diseases, including COPD and asthma. ${ }^{5,6}$ The high prevalence of suboptimal inhaler technique is supported by a recent systematic review. The review found that despite many teaching and training programs available for COPD patients, poor inhaler technique remains common and has not improved over 40 years from 1975 to $2014 .^{7}$

For COPD, the literature supports the vital role of pharmacists in educating and counseling patients. ${ }^{8,9}$ With knowledge of both diseases and medicines, pharmacists can help patients to better understand their condition(s) and the importance of each medication. COPD patients tend to have better medication adherence with pharmacist counseling, subsequently improving their quality of life as well as clinical outcomes. ${ }^{9}$ More specifically, previous studies ${ }^{8,11}$ have demonstrated the positive impact of pharmacists on improving inhaler device technique with COPD and asthma patients. Direct education by pharmacists has been shown to be more effective than other teaching methods, including watching videos and providing inhaler pamphlets. ${ }^{8}$

Although the role of pharmacists in the management of COPD has expanded recently, ${ }^{8,10,11}$ there are only a few studies that specifically focus on the role of pharmacists in counseling and educating COPD patients in developing countries. Vietnam is a typical example of a developing country where health care resources are heavily constrained, and the role of pharmacists is limited mainly to dispensing in pharmacies and hospitals. However, in Vietnam, there is a national program for the management of asthma and COPD in operation for $\sim 7$ years with very limited involvement of pharmacists. ${ }^{12}$ With increasing number of COPD patients, individualized counseling for patients is a challenge to the limited number of physicians. The potential contribution of pharmacists to the COPD management program to produce better patient outcome is yet to be explored. Since the correct inhaler technique is crucial to delivering positive outcomes in COPD and asthma, the most logical approach would be to assess the role of pharmacists' intervention to improving the inhaler technique among patients. Therefore, the objective of our study was to evaluate the impact of pharmacists' training on the improvement of the inhaler technique for COPD patients enrolled in the national program for management of asthma and COPD in Vietnam. Besides Vietnam, the results of the current study would be applicable in other countries/ jurisdictions in informing clinical pharmacy practice.

\section{Patients and methods Study participants}

The study was conducted in Bach Mai Hospital in Hanoi where a national program for management of COPD has been running for 7 years. All patients recorded in the list of COPD outpatients attending the COPD program from January to December 2016 were invited to participate in the study during their monthly medical consultation. To be eligible, the patients needed to satisfy the study inclusion criteria that include the following: had a diagnosis of COPD by the physician, attended the COPD program at least once per month and had at least one inhaler medication including metered-dose inhaler (MDI) and/or Turbuhaler ${ }^{\circledR}$ (AstraZeneca plc, London, UK) prescribed for COPD. The exclusion criteria included patients with serious visual, hearing and communication problems; deficit of mental function; at end stage of serious diseases such as cancer; attending other programs related to pulmonary diseases and unable or unwilling to provide written informed consent. All eligible patients provided signed consent forms before enrolling in the study.

\section{Study design}

The study was designed as a pre- and post-intervention study. The study was approved by the Scientific and Ethics Committee of Bach Mai Hospital and Human Research Ethics Committee of the University of Newcastle, Australia (number H-2015-0333).

\section{Develop checklist and scoring of inhaler technique}

The checklist step of each inhaler device (MDI, and dry powder inhaler [DPI] Turbuhaler; Tables 1 and 2) was derived from COPD guidelines ${ }^{1,13}$ and published literature. ${ }^{14-16}$ In order to assess the use of the inhaler devices quantitatively, we assigned a score to each correct step. As all the steps were considered important to achieving optimal medication delivery, they were, therefore, allocated equal weighting and assigned a score of 1 point each. Hence, the maximum score that patients could attain was 8 points when they used the inhaler devices correctly in every step.

\section{Setting and training description}

Participating patients were invited to meet the pharmacists in a counseling room in the hospital after their medical consultation and obtaining their medicines from the hospital pharmacy. During the pharmacist's counseling, relevant personal data, such as age, gender, education level and 
Table I Number of patients (\%) who showed technique improvement in MDI usage, sorted by steps

\begin{tabular}{|c|c|c|c|c|c|}
\hline Steps of MDI usage & T0 $(n=208)$ & $\operatorname{TI}(n=163)$ & $T 2(n=163)$ & T3 $(n=139)$ & $T 4(n=102)$ \\
\hline Step I. Remove the cap & $208(100)$ & $163(100)$ & $163(100)$ & $139(100)$ & $102(100)$ \\
\hline Step 2. Shake inhaler well & $157(75.5)$ & $\begin{array}{l}157(96.3) \\
p<0.001\end{array}$ & $\begin{array}{l}155(95.1) \\
p<0.001\end{array}$ & $\begin{array}{l}|3|(94.2) \\
p<0.00 \mid\end{array}$ & $\begin{array}{l}96(94.1) \\
p=0.001\end{array}$ \\
\hline Step 3. Hold inhaler upright & $192(92.3)$ & $\begin{array}{l}159(97.5) \\
p=0.057\end{array}$ & $\begin{array}{l}159(97.5) \\
p=0.057\end{array}$ & $\begin{array}{l}138(99.3) \\
p=0.012\end{array}$ & $\begin{array}{l}101(99.0) \\
p=0.008\end{array}$ \\
\hline Step 4. Breathe out all the way & $50(24.0)$ & $\begin{array}{l}\text { 71 (43.6) } \\
p<0.001\end{array}$ & $\begin{array}{l}104 \text { (63.8) } \\
p<0.001\end{array}$ & $\begin{array}{l}88(63.3) \\
p<0.001\end{array}$ & $\begin{array}{l}48(47.1) \\
p=0.002\end{array}$ \\
\hline $\begin{array}{l}\text { Step } 5 . \text { Place the inhaler mouthpiece between your } \\
\text { lips (and teeth) }\end{array}$ & $195(93.8)$ & $158(96.9)$ & $162(99.4)$ & $139(100)$ & $102(100)$ \\
\hline $\begin{array}{l}\text { Step 6. Prime the inhaler just after starting a very } \\
\text { slow and very deep breath in (until the lungs are full) }\end{array}$ & $102(49.0)$ & $\begin{array}{l}109(66.9) \\
p=0.003\end{array}$ & $\begin{array}{l}|4|(86.5) \\
p<0.00 \mid\end{array}$ & $\begin{array}{l}130 \text { (93.5) } \\
p<0.00 \mid\end{array}$ & $\begin{array}{l}75(73.5) \\
p<0.001\end{array}$ \\
\hline $\begin{array}{l}\text { Step } 7 \text {. Remove the inhaler from your mouth and } \\
\text { hold your breath } 5 \text { seconds (or as long as possible) }\end{array}$ & $156(75.0)$ & $\begin{array}{l}159(97.5) \\
p<0.001\end{array}$ & $\begin{array}{l}161 \text { (98.8) } \\
p<0.001\end{array}$ & $\begin{array}{l}134 \text { (96.4) } \\
p<0.00 \mid\end{array}$ & $\begin{array}{l}80(78.4) \\
p=0.864\end{array}$ \\
\hline Step 8 . Breathe out slowly & $206(99.0)$ & $162(99.4)$ & $162(99.4)$ & $139(100)$ & $102(100)$ \\
\hline
\end{tabular}

Notes: T0, baseline; TI, after I month; T2, after 3 months; T3, after 6 months and T4, after 12 months. $p$ : $p$-value of the McNemar's test for comparison of percentage between time points TI, T2, T3, T4 and T0 (analyzed when appropriate).

Abbreviation: MDI, metered-dose inhaler.

history of smoking, were first collected from the patients. Other information including years suffering from COPD, years enrolled in the national program and the level of COPD by Global Initiative for Chronic Obstructive Lung Disease (GOLD) classification ${ }^{1}$ was obtained from patients' medical records.

\section{Training description}

Face-to-face training was then conducted, with one patient to one pharmacist. Patients were asked to demonstrate their inhaler technique on placebo inhaler devices (the same devices as prescribed by their physician) in front of the pharmacist. If the patient made any mistakes, the pharmacist would correct and explain why the missing step(s) were important. The pharmacist then demonstrated to the patient every inhaler step, both verbally and physically, by using the placebo inhalers. Patients were requested to perform the technique again until they could demonstrate all steps correctly ("teach back"). The training was applied every month in the first 3 months and then repeated at the 6th month and 12th month.

\section{Sticking reminder label}

If the patients made any mistake, one additional reminder label (Box 1) that included a summary of the steps was stuck onto their inhaler device(s). Pharmacists made sure that patients were able to read the label.

\section{Assess patients' technique}

Pharmacists would assess the inhaler technique by recording and scoring the correct step(s) before the training (T0) and then reassessing the patients' inhaler technique after

Table 2 Number of patients (\%) who showed technique improvement in Turbuhaler ${ }^{\circledR}$ usage, sorted by steps

\begin{tabular}{|c|c|c|c|c|c|}
\hline Steps of Turbuhaler usage & T0 $(n=83)$ & TI $(n=63)$ & $T 2(n=52)$ & T3 $(n=42)$ & T4 $(n=39)$ \\
\hline Step I. Remove mouthpiece cover & $83(100)$ & $63(100)$ & $52(100)$ & $42(100)$ & $39(100)$ \\
\hline Step 2. Keep the inhaler upright & $81(97.6)$ & $63(100)$ & $52(100)$ & $42(100)$ & $39(100)$ \\
\hline $\begin{array}{l}\text { Step 3. Rotate the grip counter clockwise and } \\
\text { then back until a "click" is heard }\end{array}$ & $79(95.2)$ & $63(100)$ & $52(100)$ & $42(100)$ & $39(100)$ \\
\hline $\begin{array}{l}\text { Step } 4 \text {. Breathe out normally and away from } \\
\text { mouthpiece }\end{array}$ & $23(27.7)$ & $\begin{array}{l}3 \mid(49.2) \\
p=0.078\end{array}$ & $\begin{array}{l}33(63.5) \\
p<0.001\end{array}$ & $\begin{array}{l}30 \text { (7I.4) } \\
p<0.001\end{array}$ & $\begin{array}{l}20(51.3) \\
p=0.167\end{array}$ \\
\hline $\begin{array}{l}\text { Step } 5 \text {. Place the inhaler mouthpiece between } \\
\text { your lips (and teeth) }\end{array}$ & $81(97.6)$ & $63(100)$ & $52(100)$ & $42(100)$ & $39(100)$ \\
\hline Step 6. Inhale forcefully and deeply & $66(79.5)$ & $\begin{array}{l}50(79.4) \\
p=0.629\end{array}$ & $\begin{array}{l}45(86.5) \\
p=0.549\end{array}$ & $\begin{array}{l}36 \text { (85.7), } \\
p=0.998\end{array}$ & $\begin{array}{l}36(92.3) \\
p=0.016\end{array}$ \\
\hline Step 7. Hold breath for at least 5 seconds & $67(80.7)$ & $\begin{array}{l}60(95.2) \\
p=0.006\end{array}$ & $\begin{array}{l}52(100) \\
p<0.001\end{array}$ & $\begin{array}{l}42(100) \\
p=0.002\end{array}$ & $\begin{array}{l}35 \text { (89.7), } \\
p=0.344\end{array}$ \\
\hline Step 8 . Exhale normally but not through inhaler & $80(96.4)$ & $63(100)$ & $52(100)$ & $42(100)$ & $39(100)$ \\
\hline
\end{tabular}

Notes: T0, baseline; TI, after I month; T2, after 3 months; T3, after 6 months and T4, after 12 months. p: p-value of the McNemar's test for comparison of percentage between time points TI, T2, T3, T4 and T0 (analyzed when appropriate). 
Box I Reminder label of inhaler technique

\begin{tabular}{|ll|}
\hline MDI & Turbuhaler $^{\circledR}$ \\
\hline I. Remove cap & I. Remove cap \\
2. Shake well & 2. Rotate grip until hear "click" \\
$\begin{array}{l}\text { 3. Breathe out } \\
\text { 4. Breathe in + press canister }\end{array}$ & 3. Breathe out \\
and continue to breathe in & 4. Breathe in strongly and deeply \\
slowly and deeply & \\
5. Hold breath for 5 seconds & 5. Hold breath for 5 seconds \\
\hline
\end{tabular}

Abbreviation: MDI, metered-dose inhaler.

1 month (T1), 3 months (T2), 6 months (T3) and 12 months (T4) from baseline evaluation.

\section{Outcomes}

The three outcomes used to assess the impact of training were 1) percentage of patients having "correct technique," which was achieved when patients performed all the steps correctly; 2) number of patients having improvement in each step and 3) score technique improvement.

\section{Statistical analyses}

The relevant patient information and the inhaler technique scores were analyzed by using description statistics and expressed as percentages where appropriate. One-way analysis of variance, with post hoc test and paired-samples $t$-test were applied to identify the difference among mean of scores at the different time points. The McNemar's test was used for determining the difference in dichotomous dependent variables between two groups in the pre-post intervention study. Statistical significance was set at $p$-value $\leq 0.05$ (two tailed). All data were analyzed using SPSS version 22.0 (IBM Corporation, Armonk, NY, USA).

\section{Results}

\section{Sociodemographic and disease-related characteristics of study patients}

Most of the participating COPD patients were elderly subjects with a mean age of 66.6 years $( \pm 8.2$ years; Table 3$)$. As expected, there were more male patients due to the high rate of smoking in Vietnamese males (84.4\%). Approximately $70 \%$ of patients had an education level of high school or below. In addition, the majority of participants had COPD for $>3$ years. More than $90 \%$ of patients were at GOLD C and GOLD D classifications, the most severe levels of the disease. ${ }^{1}$ Approximately $80 \%$ of patients had attended the program for $>1$ year. The number of participants at the various time points is detailed in Figure 1.
Table 3 Sociodemographic and disease-related characteristics of patients participating in the study

\begin{tabular}{|c|c|}
\hline Characteristics & \\
\hline Age in years, mean $( \pm S D)$ & $66.6( \pm 8.2)$ \\
\hline \multicolumn{2}{|l|}{ Gender, n (\%) } \\
\hline Male & $178(84.4)$ \\
\hline Female & $33(15.6)$ \\
\hline \multicolumn{2}{|l|}{ Comorbidity, n (\%) } \\
\hline Yes $^{\mathrm{a}}$ & $134(63.5)$ \\
\hline No & 77 (36.5) \\
\hline \multicolumn{2}{|l|}{ Education level, n (\%) } \\
\hline Below high school & $69(32.7)$ \\
\hline High school & $75(35.5)$ \\
\hline Above high school & $67(31.8)$ \\
\hline \multicolumn{2}{|l|}{ Ever a smoker, n (\%) } \\
\hline Yes & I7| (8I.0) \\
\hline No & $40(19.0)$ \\
\hline \multicolumn{2}{|c|}{ Years suffering from COPD, n (\%) } \\
\hline$\leq 3$ & $50(23.7)$ \\
\hline$>3-5$ & $42(19.9)$ \\
\hline$>5$ & $119(56.4)$ \\
\hline \multicolumn{2}{|l|}{ GOLD classification, n (\%) } \\
\hline GOLD B & $12(5.7)$ \\
\hline GOLD C & $49(23.2)$ \\
\hline GOLD D & I50 (7I.I) \\
\hline \multicolumn{2}{|c|}{ Years attending the COPD program, $\mathrm{n}(\%)$} \\
\hline$<1$ & $5 I(24.2)$ \\
\hline $1-3$ & $92(43.6)$ \\
\hline$>3-5$ & $56(26.5)$ \\
\hline$>5$ & $12(5.7)$ \\
\hline
\end{tabular}

Notes: aHypertension, 25.6\%; osteo-related conditions, 20.2\%; gastrointestinal disorders, $10.7 \%$; hyperlipidemia, $8.3 \%$; diabetes type 2, 6.0\%; other cardiovascular diseases/conditions, $13.7 \%$ and other minor ailments, $15.5 \%$.

Abbreviations: GOLD, Global Initiative for Chronic Obstructive Lung Disease; $\mathrm{SD}$, standard deviation.

\section{Improvement of inhaler technique at each step}

Before training (T0), the percentages of patients demonstrating the correct inhaler technique were $13.9 \%$ and $20.5 \%$ for MDI and Turbuhaler, respectively (Figure 2). The training took 6 minutes on average for the first counseling session and 3 minutes after the first time. After training with pharmacists (Figure 2), the percentage of patients performing the technique correctly increased from $13.9 \%$ and $20.5 \%$ (T0) to $56.8 \%$ and $61.9 \%$ (T3) for MDI and Turbuhaler, respectively. When the period between the training was longer ( 6 months from T3 to T4), the percentage of patients having the correct technique decreased from $>61.9 \%$ to $48.7 \%$ with Turbuhaler ( $p=0.302)$. For MDI, after the 6-month period, the percentage of patients having the correct technique decreased significantly from $58.6 \%$ to $33.3 \%(p=0.002)$.

Regarding the specific steps, as shown in Tables 1 and 2 (T0), no mistakes were observed for Step 1; however, mistakes were recorded for every other step thereafter. The most 


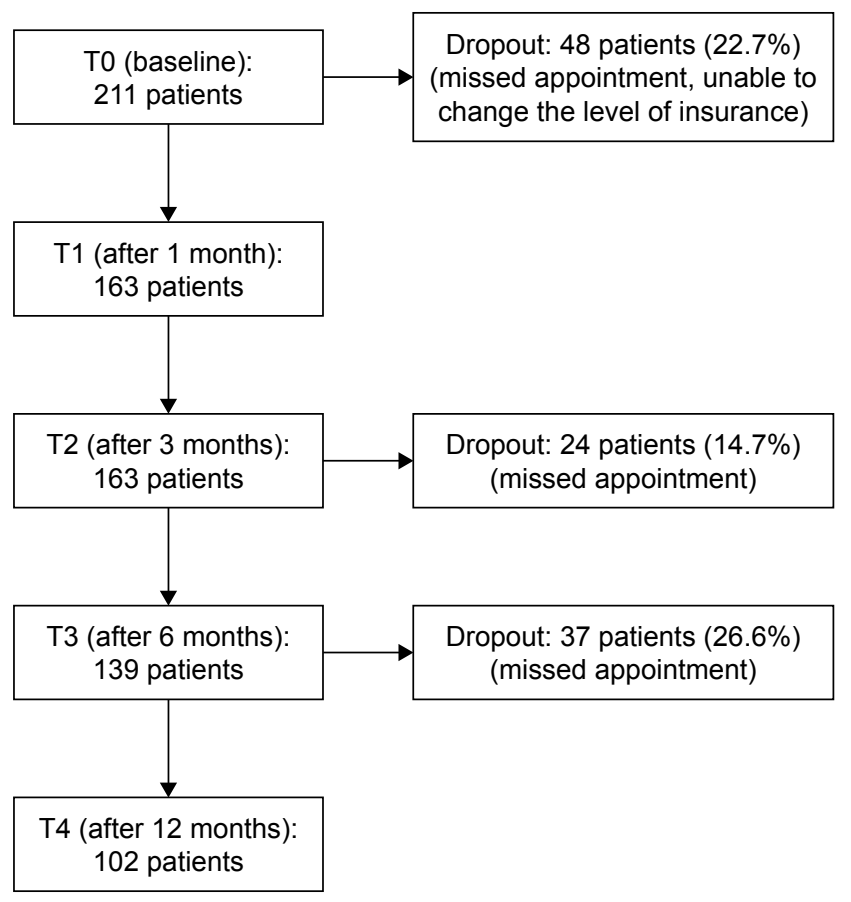

Figure I Flow diagram for the time of assessing technique and dropout rates.

common mistake for both inhaler devices was Step 4 (breathe out), with $<30 \%$ of patients remembering to perform this step. The second common mistake was Step 6 for both MDI and Turbuhaler. After training, the number of patients who performed each step correctly increased significantly.

\section{Improvement of mean inhaler technique scores}

Evaluation of the mean inhaler technique scores with MDI across the five assessment time points showed mean scores of 6.09, 6.97, 7.49, 7.49 and 6.93 for T0 (baseline), T1 (after 1 month), T2 (after 3 months), T3 (after 6 months) and T4 (after 12 months), respectively (Figure 3). Overall, there was a significant difference in patients' inhaler technique scores after training $(p<0.001)$. In particular, significant increases were observed at 1, 3, 6 and 12 months after training in comparison to baseline values (T0). Results for the Turbuhaler technique (Figure 4) were similar to those of the MDI technique. However, significant increases in scores were only observed at 3 months $(p=0.001)$ and 6 months $(p<0.001)$ after training when compared to baseline values (T0). For both inhaler devices, there was a decrease in the mean technique score from the 6th month (T3) to the 12th month (T4).

\section{Technique scores based on patient demographics}

Baseline values (T0; Table 4) showed a significant difference in technique scores among different age groups of participants ( $p=0.01$ ), with younger patients having higher overall scores. However, the scores of all patients increased significantly after attending the training program and no significant differences were observed after the $\mathrm{T} 2$ assessment time point. Before the training, years of suffering from COPD and attendance in the national program were two factors that influenced the inhaler technique score (T0; Tables 5 and 6). More specifically, patients who participated in the program for longer or those that have suffered from COPD for a longer duration had higher baseline scores $(p<0.05)$. However, the technique scores improved in all patient subgroups after the training, with no significant difference between the scores in these groups ( $p>0.05$; T1-4; Tables 5 and 6$)$.

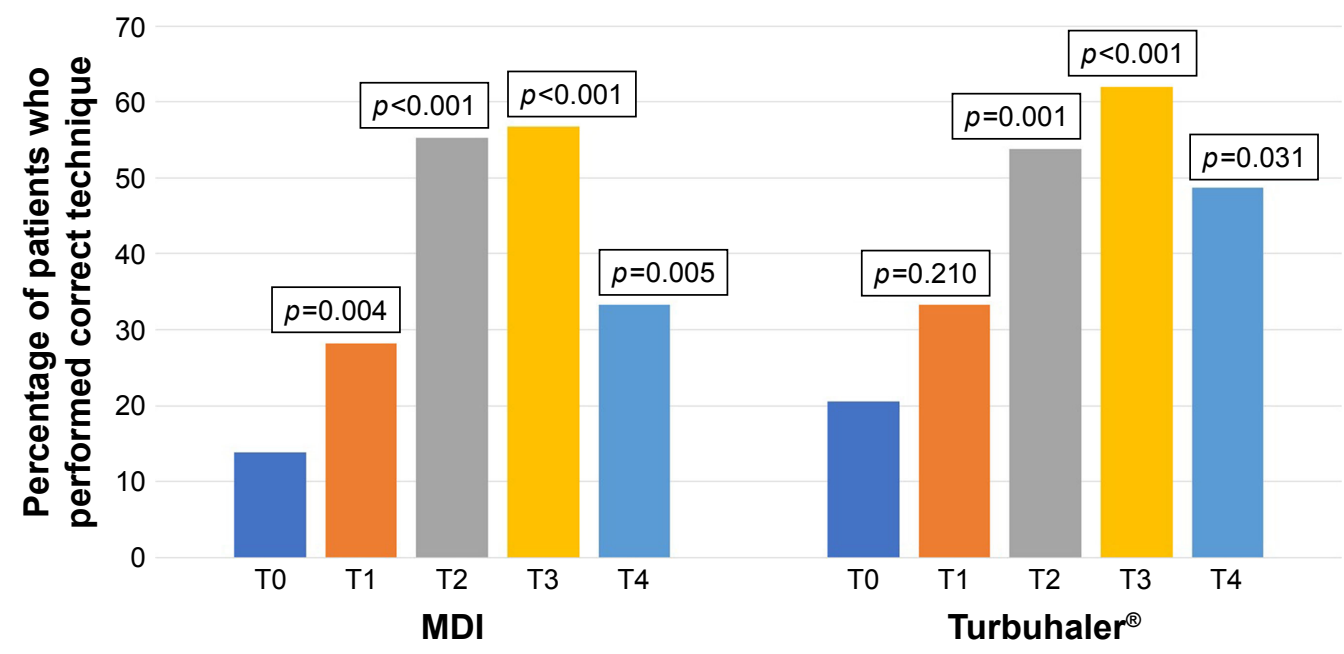

Figure 2 Comparison of the percentage of patients performing the correct inhaler technique over the study period.

Notes: T0, baseline; TI, after I month; T2, after 3 months; T3, after 6 months and T4, after 12 months. $p$ : $p$-value of the McNemar's test determined the difference in the percentage of patients who performed the correct technique (all the correct steps) between time points TI, T2, T3, T4 and T0.

Abbreviation: MDI, metered-dose inhaler. 


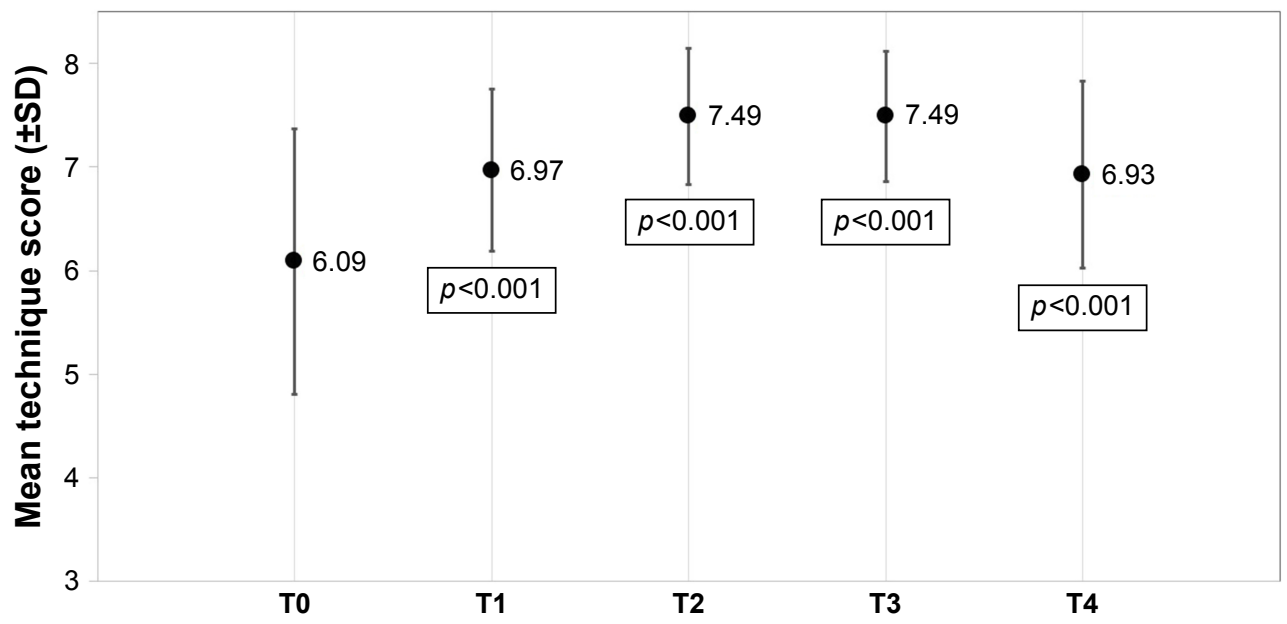

Figure 3 Comparison of the mean technique score for MDI across the study period.

Notes: T0, baseline; TI, after I month; T2, after 3 months; T3, after 6 months and T4, after 12 months. p: p-value of ANOVA and post hoc tests in comparison of the score between after the training (TI, T2, T3, T4) and before training (T0).

Abbreviations: ANOVA, analysis of variance; MDI, metered-dose inhaler; SD, standard deviation.

\section{Discussion}

To the best of our knowledge, the present study is the first to evaluate the role of pharmacists in educating COPD patients to correctly use their inhaler devices in a developing country. Our results showed that COPD patients' inhaler technique improved significantly after receiving training from pharmacists. In our study, $>85 \%$ of MDI users and $80 \%$ of DPI-Turbuhaler users in the national COPD program used inhaler devices incorrectly prior to training (T0). This is consistent with other published findings in COPD patients including those from developed countries. ${ }^{7,15,17}$ Thus, our results have highlighted that mishandlings of inhaler medications are common among COPD patients and, as shown in previous studies, are likely to negatively impact on COPD management. ${ }^{15,18-20}$

Participants made the most errors in Steps 4, 6 and 7 for both inhaler devices. Step 4 (breathe out all the way) is important for helping to deposit drug molecules deeper into the airways but recorded the highest error rate in our study ( $>70 \%$ of patients). Likewise, Lavorini et a ${ }^{21}$ showed that "No exhalation before inhalation" was the most frequent error made by asthma and COPD patients using all common DPIs (including Turbuhaler), and $50 \%$ of users did not exhale before actuation when using MDIs in another study of 1,664 patients conducted by Melani et al. ${ }^{5}$ Step 6 focuses on the method of inhalation. While all MDIs require users

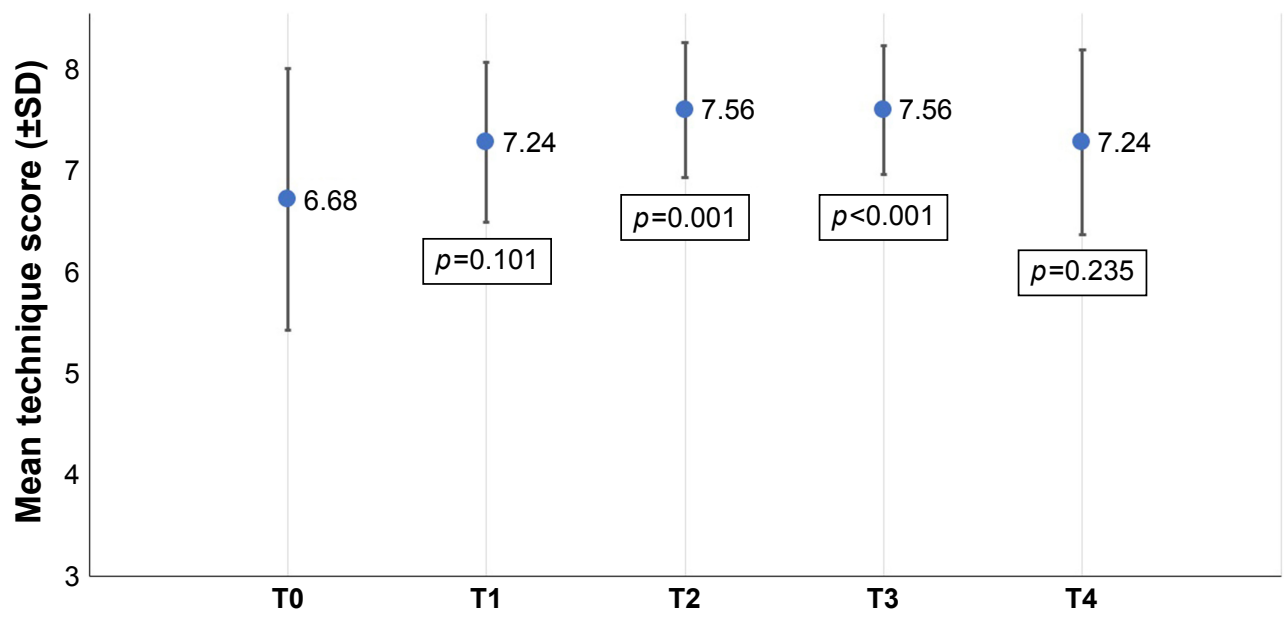

Figure 4 Comparison of the mean technique score for Turbuhaler ${ }^{\circledR}$ across the study period.

Notes: T0, baseline; TI, after I month; T2, after 3 months; T3, after 6 months and T4, after 12 months. p: p-value of ANOVA and post hoc tests in comparison of the score between TI, T2, T3, T4 and T0.

Abbreviations: ANOVA, analysis of variance; SD, standard deviation. 
Table 4 Patients' age and improvement in technique score with MDI

\begin{tabular}{lllll}
\hline Time & $\begin{array}{l}<6 \text { years, } \\
\text { mean }( \pm \text { SD) }\end{array}$ & $\begin{array}{l}\mathbf{6 0 - 7 5} \text { years, } \\
\text { mean }( \pm \text { SD) }\end{array}$ & $\begin{array}{l}>\text { 75 years, } \\
\text { mean }( \pm \text { SD) }\end{array}$ & p-value \\
\hline T0 & $6.77(0.94)$ & $6.00(1.25)$ & $6.10(1.96)$ & 0.01 \\
T1 & $7.19(0.75)$ & $6.96(0.81)$ & $6.85(1.07)$ & 0.32 \\
T2 & $7.50(0.65)$ & $7.45(0.71)$ & $7.05(1.11)$ & 0.04 \\
T3 & $7.78(0.42)$ & $7.41(0.74)$ & $7.39(0.79)$ & 0.07 \\
T4 & $6.81(0.91)$ & $6.93(0.90)$ & $7.00(0.91)$ & 0.84 \\
\hline
\end{tabular}

Notes: T0, baseline; TI, after I month; T2, after 3 months; T3, after 6 months and T4, after 12 months. p: $p$-value of the ANOVA test for comparison of mean score between age groups.

Abbreviations: ANOVA, analysis of variance; MDI, metered-dose inhaler; SD, standard deviation.

to breathe in slowly at the same time as pressing down on the inhaler, DPIs need forceful and deep inspiration..$^{14,16}$ More than $50 \%$ of our study patients had problems with this coordination. In fact, the lack of hand-lung synchronization is the main error reported for using MDIs and is considered as the most difficult step for patients, especially the elderly., ${ }^{6,14,17,19}$ More patients performed Step 6 correctly using DPI-Turbuhaler devices (70.1\%) compared to MDIs $(47.1 \%)$ in our study. This again is consistent with other studies, ${ }^{14,15,22,23}$ where significantly more patients made more critical errors using MDIs than patients using other devices, including Turbuhaler. ${ }^{15}$ Unlike MDIs, there is no need to coordinate the delivery of aerosol drug with an inspiration with DPIs. Therefore, correctly using DPIs is relatively easier than using MDIs. ${ }^{14,22,23}$

After training with pharmacists, our results showed significant improvement in the inhaler technique of COPD patients in both steps and scores. Patients who correctly performed the step checklists increased after each visit with the pharmacist. More importantly, patients made less mistakes in Steps 4, 6 and 7, the most error-prone steps before training. Furthermore, there was a dramatic increase in patients' overall technique scores when using both MDI

Table 5 Years of suffering from COPD and improvement in technique score with MDI

\begin{tabular}{lllll}
\hline Time & $\begin{array}{l}\leq \text { 3 years, } \\
\text { mean }( \pm \mathbf{S D})\end{array}$ & $\begin{array}{l}>\mathbf{3}-\mathbf{5} \text { years, } \\
\text { mean }( \pm \mathbf{S D})\end{array}$ & $\begin{array}{l}>\mathbf{5} \text { years, } \\
\text { mean }( \pm \mathbf{S D})\end{array}$ & p-value \\
\hline T0 & $5.69(1.50)$ & $5.90(1.16)$ & $6.31(1.22)$ & $0.0 \mathrm{I}$ \\
TI & $6.97(0.80)$ & $6.97(0.9 \mathrm{I})$ & $6.99(0.83)$ & 0.98 \\
T2 & $7.44(0.56)$ & $7.29(0.86)$ & $7.44(0.80)$ & 0.63 \\
T3 & $7.35(0.84)$ & $7.26(0.66)$ & $7.58(0.67)$ & 0.08 \\
T4 & $6.95(1.02)$ & $7.00(0.98)$ & $6.88(0.83)$ & 0.85 \\
\hline
\end{tabular}

Notes: T0, baseline; TI, after I month; T2, after 3 months; T3, after 6 months and T4, after 12 months. $p$ : $p$-value of the ANOVA test for comparison of mean score between groups with different periods of suffering from COPD.

Abbreviations: ANOVA, analysis of variance; MDI, metered-dose inhaler; SD, standard deviation. and DPI Turbuhaler. The results of subgroup analysis also illustrated that the pharmacists' training made equal impact upon the inhaler technique in different patient subgroups (Tables 4-6). These findings are consistent with other published literature. ${ }^{9,16,24-27}$

Quantitative scoring of the inhaler technique was used in this study to facilitate simpler and more consistent evaluation. Health workers and caregivers just need to check the steps by scoring 1 point for each correct step and 0 for each incorrect step. Even family members of patients can use the checklist to score and report to health professionals. The scoring inhaler technique has also been utilized in previous studies. ${ }^{916,24,25}$ These studies allocated points to each inhaler technique step based on its level of significance in the overall process. ${ }^{15,28}$ Hence, it is critical to define which step (classified as critical step) would lead to little or no medication reaching the lungs if performed incorrectly. ${ }^{15,17}$ However, there is no clear agreement on the importance of each step as shown by the many checklists used in the assessment of the inhaler technique in published studies and clinical practice. A review by Basheti et $\mathrm{al}^{28}$ compared 24 checklists for the appropriate use of DPI Turbuhaler and found a substantial variation in the number of steps listed (ranging from 3 to 14 steps), as well as different critical steps identified in 10 of the checklists. Besides likely to create inconsistency between evaluators, focusing on critical steps may also lead assessors to ignore "less important" steps that may significantly affect drug delivery. ${ }^{17}$ Therefore, equal scoring of the inhalation steps used in our study appears to be a more suitable method for its simplicity and consistency when applied in clinical practice.

Pharmacists are important health educators and are in the best strategic position in counseling patients during the patient's clinical consultation process. Medication counseling by pharmacists has been demonstrated to be more effective than other methods such as watching videos or reading pamphlets. ${ }^{8}$ However, in developing countries like Vietnam, pharmacists are widely underutilized in the health care team with their role mainly limited as a dispenser of medicines. Therefore, our findings provide evidence of their valuable contribution to improving the inhaler technique in COPD patients. With the increasing prevalence of COPD in Vietnam and the low doctor-to-patients ratio, involvement of pharmacists would be a solution for the lack of health professionals and a strategy to better employment of an underutilized resource in the overcrowded hospitals. ${ }^{12,29}$

The training applied in our present study was specially chosen to cater for COPD patients who are generally older 
Table 6 Years of attending the program and improvement in technique score with MDI

\begin{tabular}{|c|c|c|c|c|c|}
\hline Time & $\begin{array}{l}<\mathrm{I} \text { year, } \\
\text { mean }( \pm \mathrm{SD})\end{array}$ & $\begin{array}{l}\text { I-3 years, } \\
\text { mean }( \pm S D)\end{array}$ & $\begin{array}{l}>3-5 \text { years, } \\
\text { mean }( \pm S D)\end{array}$ & $\begin{array}{l}>5 \text { years, } \\
\text { mean }( \pm S D)\end{array}$ & $p$-value \\
\hline T0 & $5.65(1.64)$ & $6.14(1.08)$ & $6.30(1.22)$ & $6.42(1.38)$ & 0.04 \\
\hline TI & $7.14(0.83)$ & $6.91(0.87)$ & $6.93(0.77)$ & $7.38(0.74)$ & 0.33 \\
\hline T2 & $7.45(0.67)$ & $7.30(0.82)$ & $7.48(0.75)$ & $8.00(0.00)$ & 0.08 \\
\hline T3 & $7.62(0.57)$ & $7.36(0.78)$ & $7.49(0.68)$ & $7.83(0.4 I)$ & 0.25 \\
\hline T4 & $7.10(0.85)$ & $6.96(0.95)$ & $6.78(0.85)$ & $6.60(0.89)$ & 0.54 \\
\hline
\end{tabular}

Notes: T0, baseline; TI, after I month; T2, after 3 months; T3, after 6 months and T4, after 12 months. p: p-value of the ANOVA test for comparison of mean score between groups with different periods of attending the program.

Abbreviations: ANOVA, analysis of variance; MDI, metered-dose inhaler; SD, standard deviation.

and have additional comorbidities. The first method was face-to-face training of COPD patients by the pharmacists. "One pharmacist-to-one patient" training has been described as the best method to teach patients how to use inhalers properly. ${ }^{16,30}$ Second, "Teach-back" has also been shown to be an effective method for COPD patients by evaluating their understanding of the inhalation technique as they practiced using the inhaler in front of pharmacists..$^{30}$ Third, our study is the first to apply the use of "inhaler reminder labels" for COPD patients. This method has previously been applied successfully in other studies of asthma patients using DPI Turbuhaler and Diskus. ${ }^{16}$ The label helped patients to better remember the correct technique. ${ }^{27}$ This was considered as a better method than providing patients with other take-home materials such as video instructions or medication leaflets containing excessive information. ${ }^{16,27}$ However, unlike previous studies, we used labels with a larger font size and patients were asked to confirm that they could read the label clearly. A larger font size would increase noticeability and readability and has been shown to be effective in improving compliance. ${ }^{31,32}$ Hence, our reminder label with a larger font size may also contribute positively to better inhaler technique in combination with direct training.

Repeated training is crucial to maintaining proper inhaler technique and is recommended by respiratory experts and guidelines. ${ }^{1}$ However, there is no consensus of exact period of time for regular checks and training for assuring proper maintenance. It has been suggested that checks should be performed every 1-3 months, or every time a patient visit their doctor or pharmacy. ${ }^{24}$ In our study, we initially reviewed the patients' technique intensively every month for the first 3 months and then at 6 months and 12 months. Intensive training at the beginning of inhaler use is very important, as it is difficult for COPD patients to remember all the steps at the first meeting. ${ }^{33}$ Furthermore, forgetfulness commonly occurs especially in older patients. ${ }^{34}$ Thus, it is necessary to repeat the checking and training process for the inhaler technique along with other outcomes of COPD. Our findings suggest that complete training should be repeated every 3 months after the first intensive period, as our study showed an increased number of patients making mistakes and a decrease in technique scores for both inhaler devices 6 months after intensive training (ie, T3 to T4 of our study time points). Therefore, this suggested that a 3 -month period would be the optimal time for retraining after the initial intensive training.

Our study also showed that the application of these pharmacists' interventions for COPD patients is feasible as part of pharmacists' everyday duties. The average time for the first meeting was $\sim 6$ minutes, which included time for checking inhaler technique, pointing out incorrect steps, asking the patient to demonstrate inhaler use again and sticking a technique label to the device if necessary. The duration of the second and third visits gradually decreased to $\sim 3$ minutes. The time taken in our study is similar to the time of intervention recorded in another study. ${ }^{16}$ Basheti et $\mathrm{a}^{16}$ reported a median time taken for inhaler technique intervention of 5 minutes ( \pm 2 minutes) for the first meeting and 2 minutes and 1 minute for the second and third visits, respectively.

This is the first study that has evaluated the impact of pharmacist-led training to improving the proper use of inhaler devices for COPD patients in a developing country. We have developed a comprehensive method that is suitable for training a diversity of population groups, including older patients, in order to optimize effectiveness of inhaler devices. We have also applied an unbiased and simple scoring method for assessing outcomes, as well as identified an appropriate period of time for retraining patients to maintain the correct inhaler technique. There are several limitations in our study. First, the study only included patients enrolled in the national program, which may overestimate the ability of the general COPD patients who would have less support than those in the program. Second, the study has not yet correlated the 
improvement in the inhaler technique with clinical outcomes. Clinical improvement depends on many factors such as drug selection, patient compliance and control of other risk factors including the environment and nutrition. Nevertheless, proper inhaler use has been shown to be closely related to improving clinical outcomes of COPD patients. ${ }^{5}$ Third, the relative high dropout rate $(-50 \%)$ may also affect the robustness of our study results. However, we had also analyzed the data only for the patients who were assessed at every assessment point, and the results did not differ. Furthermore, we also compared the demographic and other characteristics between dropout and non-dropout groups and again found no significant difference except in age. Although the dropout group was slightly younger, the mean ages of both groups were similar to the total group. An inference from these additional analyses would be that the high dropout rate did not affect our final results.

\section{Conclusion}

Our study showed that a pharmacist-led comprehensive inhaler technique intervention program using an unbiased and simple scoring system can significantly improve the inhaler techniques in COPD patients. We also identified an optimal time period between training and retraining for maintaining the correct inhaler technique. Our model of pharmacist-led training should be considered as an effective solution for managing COPD patients and better utilization of human resources in health care, especially in a developing country like Vietnam.

\section{Acknowledgments}

The authors would like to thank patients for participating in the study and pharmacists of the Department of Pharmacy, Bach Mai Hospital, for training patients, especially Mrs Nguyen Hoai Thu, Miss Do Thi Thu Hien and Miss Kim Huyen Trang. The authors also wish to thank the Board of Directors of Bach Mai Hospital and members of Department of Clinical Pharmacy, Hanoi University of Pharmacy, for supporting the study.

\section{Author contributions}

All authors contributed to tool development and study design, data analysis, drafting and revising the manuscript, gave final approval of the manuscript version to be published, and agreed to be accountable for all aspects of the work.

\section{Disclosure}

The authors report no conflicts of interest in this work.

\section{References}

1. Global initiative for Chronic Obstructive Lung Disease (GOLD). Global Strategy for the Diagnosis Management and Prevention of Chronic Obstructive Pulmonary Disease; 2017 [updated 2017]. Available from: http:/goldcopd.org/gold-2017-global-strategy-diagnosis-managementprevention-copd/. Accessed March 30, 2017.

2. Ait-Khaled N, Enarson D, Bousquet J. Chronic respiratory diseases in developing countries: the burden and strategies for prevention and management. Bull World Health Organ. 2001;79(10):971-979.

3. Ministry of Health. National Program for Management of Chronic Respiratory Diseases in Vietnam; 2015. Available from: http://benhphoitacnghen. vn/hoi-nghi-khoa-hoc-va-le-mit-tinh-huong-ung-ngay-hen-toan-cau-2018. html. Accessed May 23, 2018. Vietnamese.

4. Le TTL. The actuality of chronic obstructive pulmonary disease in Vietnam. J Fr Vietnam Assoc Pulmonol. 2011;2(04):46-48.

5. Melani AS, Bonavia M, Cilenti V, et al. Inhaler mishandling remains common in real life and is associated with reduced disease control. Respir Med. 2011;105(6):930-938.

6. Sriram KB, Percival M. Suboptimal inhaler medication adherence and incorrect technique are common among chronic obstructive pulmonary disease patients. Chron Respir Dis. 2016;13(1):13-22.

7. Sanchis J, Gich I, Pedersen S; Aerosol Drug Management Improvement Team (ADMIT). Systematic review of errors in inhaler use: has patient technique improved over time? Chest. 2016;150(2):394-406.

8. Axtell S, Haines S, Fairclough J. Effectiveness of various methods of teaching proper inhaler technique. J Pharm Pract. 2017;30(2):195-201.

9. Tommelein E, Mehuys E, Van Hees T, et al. Effectiveness of pharmaceutical care for patients with chronic obstructive pulmonary disease (PHARMACOP): a randomized controlled trial. Br J Clin Pharmacol. 2014;77(5):756-766.

10. Zhong H, Ni XJ, Cui M, Liu XY. Evaluation of pharmacist care for patients with chronic obstructive pulmonary disease: a systematic review and meta-analysis. Int J Clin Pharm. 2014;36(6):1230-1240.

11. Hammerlein A, Muller U, Schulz M. Pharmacist-led intervention study to improve inhalation technique in asthma and COPD patients. $J$ Eval Clin Pract. 2011;17(1):61-70.

12. Vietnam Ministry of Health, Health Partnership Group; Hanoi: Medical Publishing House; 2015. Joint Annual Health Review 2014: Strengthening prevention and control of non-communicable Disease. Available from: http://www.jahr.org.vn/downloads/JAHR2014/JAHR\%20 2014_EN_full.pdf. Accessed May 23, 2018.

13. Ministry of Health. Vietnamese Guideline for Diagnosis and Treatment of Chronic Obstructive Pulmonary Disease. 2015. (No 2866/QĐ-BYT). Hanoi: Medical Publishing House; 2015.

14. Sanchis J, Corrigan C, Levy ML, Viejo JL; ADMIT Group. Inhaler devices - from theory to practice. Respir Med. 2013;107(4):495-502.

15. Batterink J, Dahri K, Aulakh A, Rempel C. Evaluation of the use of inhaled medications by hospital inpatients with chronic obstructive pulmonary disease. Can J Hosp Pharm. 2012;65(2):111-118.

16. Basheti IA, Armour CL, Bosnic-Anticevich SZ, Reddel HK. Evaluation of a novel educational strategy, including inhaler-based reminder labels, to improve asthma inhaler technique. Patient Educ Couns. 2008;72(1):26-33.

17. Molimard M, Raherison C, Lignot S, Depont F, Abouelfath A, Moore N. Assessment of handling of inhaler devices in real life: an observational study in 3811 patients in primary care. $J$ Aerosol Med. 2003;16(3):249-254.

18. Dudvarski Ilic A, Zugic V, Zvezdin B, et al. Influence of inhaler technique on asthma and COPD control: a multicenter experience. Int $J$ Chron Obstruct Pulmon Dis. 2016;11:2509-2517.

19. Pothirat C, Chaiwong W, Phetsuk N, Pisalthanapuna S, Chetsadaphan N, Choomuang W. Evaluating inhaler use technique in COPD patients. Int J Chron Obstruct Pulmon Dis. 2015;10:1291-1298.

20. Arora P, Kumar L, Vohra V, et al. Evaluating the technique of using inhalation device in COPD and bronchial asthma patients. Respir Med. 2014;108(7):992-998. 
21. Lavorini F, Magnan A, Dubus JC, et al. Effect of incorrect use of dry powder inhalers on management of patients with asthma and COPD. Respir Med. 2008;102(4):593-604.

22. Quinet $P$, Young CA, Heritier F. The use of dry powder inhaler devices by elderly patients suffering from chronic obstructive pulmonary disease. Ann Phys Rehabil Med. 2010;53(2):69-76.

23. Khassawneh BY, Al-Ali MK, Alzoubi KH, et al. Handling of inhaler devices in actual pulmonary practice: metered-dose inhaler versus dry powder inhalers. Respir Care. 2008;53(3):324-328.

24. Thomas RP, Rani NV, Kannan G, Thennarasu P, Mohammed S. Impact of pharmacist-led continuous education on the knowledge of inhalation technique in asthma and COPD patients. Int J Med Health Sci. 2015;4(1):7.

25. Goris S, Tasci S, Elmali F. The effects of training on inhaler technique and quality of life in patients with COPD. J Aerosol Med Pulm Drug Deliv. 2013;26(6):336-344.

26. Nguyen NT, Nguyen TTN. Evaluation of the metered-dose inhaler technique in the patients with asthma and COPD. Med $J$ Hochiminh City. 2003;7(1):103-109.

27. Basheti IA, Obeidat NM, Reddel HK. Effect of novel inhaler technique reminder labels on the retention of inhaler technique skills in asthma: a single-blind randomized controlled trial. NPJ Prim Care Respir Med. 2017;27(1):9.
28. Basheti IA, Bosnic-Anticevich SZ, Armour CL, Reddel HK. Checklists for powder inhaler technique: a review and recommendations. Respir Care. 2014;59(7):1140-1154.

29. Vo TH, Bedouch P, Nguyen TH, et al. Pharmacy education in Vietnam. Am J Pharm Educ. 2013;77(6):114.

30. Press VG, Arora VM, Shah LM, et al. Teaching the use of respiratory inhalers to hospitalized patients with asthma or COPD: a randomized trial. J Gen Intern Med. 2012;27(10):1317-1325.

31. Hellier E, Edworthy J, Derbyshire N, Costello A. Considering the impact of medicine label design characteristics on patient safety. Ergonomics. 2006;49(5-6):617-630.

32. Liu F, Abdul-Hussain S, Mahboob S, Rai V, Kostrzewski A. How useful are medication patient information leaflets to older adults? A content, readability and layout analysis. Int J Clin Pharm. 2014;36(4): 827-834.

33. Takaku Y, Kurashima K, Ohta C, et al. How many instructions are required to correct inhalation errors in patients with asthma and chronic obstructive pulmonary disease? Respir Med. 2017;123:110-115.

34. Wallin M, Tagami T, Chen L, Yang M, Chan HK. Pulmonary drug delivery to older people. Adv Drug Deliv Rev. Epub 2017 Nov 29.
International Journal of COPD

\section{Publish your work in this journal}

The International Journal of COPD is an international, peer-reviewed journal of therapeutics and pharmacology focusing on concise rapid reporting of clinical studies and reviews in COPD. Special focus is given to the pathophysiological processes underlying the disease, intervention programs, patient focused education, and self management protocols.

\section{Dovepress}

This journal is indexed on PubMed Central, MedLine and CAS. The manuscript management system is completely online and includes a very quick and fair peer-review system, which is all easy to use. Visit http://www.dovepress.com/testimonials.php to read real quotes from published authors. 